\title{
COMPARISON OF MINI CHOLECYSTECTOMY VERSUS CONVENTIONAL OPEN CHOLECYSTECTOMY IN PATIENTS WITH CHOLELITHIASIS
}

\author{
Uzair Karim Qaisrani ${ }^{a}$, Muhammad Faizan ${ }^{b}$, Zarnab Siddique ${ }^{c}$, Muhammad Khalid ${ }^{d}$, Kiran Bashir $^{\mathrm{e}}$, Asim Bhatti ${ }^{\mathrm{f}}$ \\ ${ }^{a}$ Consultant Surgeon, Department of General Srugery, DGKMC Dera Ghazi Khan. \\ ${ }^{b}$ Medical Officer, THQ Hospital Kot Chutta, Dera Ghazi Khan. \\ 'Women Medical Officer, THQ Taunsa Sharif, Dera Ghazi Khan.

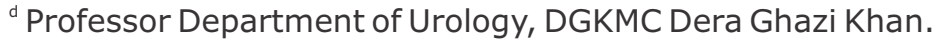 \\ ${ }^{e}$ Women Medical Officer, Rural Health Center Sarwar Wali, Dera Ghazi Khan. \\ ${ }^{f}$ Assistant Professor, Department of General Surgery, DGKMC Dera Ghazi Khan.
}

\section{ABSTRACT:}

BACKGROUND \& OBJECTIVES: The goal of this study is to compare the results of mini cholecystectomy with open conventional cholecystectomy in the management of cholelithiasis.

METHODOLOGY: A total of 100 cases; 50 cases in each group was included in the study. 100 patients were admitted from OPD of Teaching Hospital Dera Ghazi Khan fulfilling inclusion criteria. Demographic information was recorded. All admitted patients were diagnosed after taking history and performing clinical examination. Written consent was obtained. Statistical data input and scrutiny done with the help of SPSS 11 . All the Information was inspected by the proposed investigation plan.

RESULTS: Mean age of all patients was 39.96 \pm 3.84 years. Age range of patients was 30-48 years. In Group-A (Mini Cholecystectomy Patients) mean hospital stay was 5.38 \pm 1.15 and in Group-B (Conventional Cholecystectomy Patients) mean hospital stay was $3.02 \pm 0.58$ days respectively. At 1 st visit $14(28 \%)$ patients in Group-B and only $1(2 \%)$ patient in Group-A had wound infection. According to P-value wound infection was significantly correlated with treatment group. Patients in Group-A had less infection rate in comparison to Group-B patients. i.e. (P-value $=0.000$ ) whereas at 2nd visit $8(16 \%)$ patients in Group-B and 3 patients in Group-A suffered from wound infection. At 2nd visit wound infection was statistically same in both treatment groups. i.e. (P-value $=0.110)$. It was observed that in Group-B 44(88\%) of the patients had severe pain whereas only $12(24 \%)$ of the patients in Group-A had severe pain. Keeping in mind this results rate of severe pain at 12 th hour was high in Group-B patients in contrast to Group-A patients. i.e. (P-value $=0.000$ ).

CONCLUSION: Mini cholecystectomy is effective and related with less patient's uneasiness in terms of post-operative pain and infection as well as with less hospital stay.

KEYWORDS: Cholelithiasis, Conventional, Cholecystectomy, Laparoscopic, Mini laparoscopic.

\section{How to cite this:}

https://doi.org/10.37723/jumdc.v11i2.410

Qaisrani UK, Faizan M, Siddique Z, Khalid M, Bashir K, Bhatti A. COMPARISON OF MINICHOLECYSTECTOMY VERSUS OPEN CHOLECYSTECTOMY IN PATIENTS WITH CHOLELITHIASIS. jumdc. $2020 ; 11(2): 34-42$.

doi: https://doi.org/10.37723/jumdc.v11i2.410

This is an Open Access article distributed under the terms of the Creative Commons Attribution License (http://creativecommons.org/licenses/by/4.0), which permits unrestricted use, distribution, and reproduction in any medium, provided the original work is properly cited. 


\section{INTRODUCTION:}

Cholelithiasis is the well-known problem of the hepatobiliary system and cholecystectomy the commonest surgical intervention ${ }^{[1]}$. The first ever successful cholecystectomy was performed by Carl Langenbuch ${ }^{[2]}$. Tradionally cholecystectomy is being done through an incision approximately 3-4 inches long. It cuts the muscles. Since then so many incisions for cholecystectomy have been described, the most commonly used is Kocher subcostal incision $3 \mathrm{~cm}$ from midline and $2 \mathrm{~cm}$ below right subcostal almost $5-7 \mathrm{~cm}$ in lenght. The incisions provide generous exposure to be ligated. Eight thoracic nerve and its branches are usually divided (Dorfman et al, 1997). Although exposure is good but its cosmetic results are relatively poor, along with more pain and prolong hospital stay ${ }^{[3]}$.

To address these problems many people tried Mini cholecystectomy as describe by Dubois and Bertheol in 1990 for the first time ${ }^{[4]}$. They claimed that this incision has lesser postoperative pain (which is also comparable with laparoscopic cholecystectomy) ${ }^{[5,6]}$. Operative time and hospital stay are less with good cosmetic results. But disadvantage is relative poor exposure ${ }^{[7]}$.

Therefore on the subject, workers all over the world are of the different opinion as Gilliland \& Traverso, 1990 and Roslyn JJ et al., 1993 described that traditional right subcostal kocher incision is gold standard as it give good access and less complication rates. But the workers like Moss in 1983, Amir M et al., 2007, Khan N. et al 2009, and Saeed N, et al., in 2010 are of argument that mini cholecystectomy is new gold standard as for as open cholecystectomy is concerned because of less pain good cosmetic results, early return to work and less operation cost. It appears to be safe and can be used where laproscopic facilities are not available ${ }^{[8,9]}$. Different studies have shown that risk of complications in mini cholecystectomy i.e. mean hospital stay was $3.33 \pm 1.75$, sever pain was $16 \%$ and was assessed in zero postoperative day through VAS as it's a day care procedure and wound infection was $4 \%$. Whereas in case of traditional open cholecystectomy hospital stay was $8.66 \pm 4$ days, sever pain $56 \%$ and wound infection was

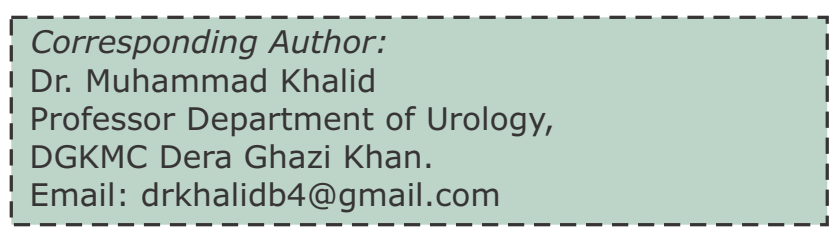

$24 \%{ }^{[10]}$.

The logic of this study is to differentiate mini cholecystectomy with that of conventional open cholecystectomy and there is only one study available conducted by Abdul Manan with sample size of 25 in each group, which is less that of this study. There are lots of comparative studies available between laparoscopic versus mini cholecystectomy ${ }^{[3,5,7,8]}$ which shows mini cholecystectomy is as effective as laparoscopic cholecystectomy, which is gold standard.

\section{METHODOLOGY}

A randomized controlled trial study with nonprobability purposive sampling was done in Department Of Surgery, Teaching Hospital Dera Ghazi Khan, from June 2017 to Dec 2017 for a period of six month. The study has been approved by the ethical review committee of Dera Ghazi Khan Medical College, Dera Ghazi Khan. An aggregate of 100 cases; 50 cases in each category is determined with $80 \%$ intensity of test, $5 \%$ level of significance and taking expected level of wound contamination for i.e $4 \%$ with mini cholecystectomy and $24 \%$ with customary cholecystectomy.

Patients of both sexes, age between 30 to 70 with diagnosis of cholelithiasis (diagnosed on the basis of history with complain of pain in right hypochondrium, and gall stones on ultrasound abdomen) medically fit for general anesthesia (ASA I and II) were included.

And following patients were excluded having associated symptoms of peritonitis, ascites, assessed by history, clinical examination and ultrasound abdomen. Patients having diabetes diagnosed as blood fasting sugar level $>110 \mathrm{mg} / \mathrm{dl}$ or patients already taking medications for this Pregnant female. Choledocholithiasis and Acute Cholecysititis. 100 patients were admitted from OPD of Teaching Hospital Dera Ghazi Khan, fulfilling inclusion criteria. Demographic information was recorded. All admitted patients were diagnosed after taking proper history and performing 
clinical examination and obtaining all necessary investigation. Written consent was obtained. Proven cases fulfilling with inclusion criteria were cleaved into two groups, Group A and Group-B with random lottery method

1.Group-A: Mini cholecystectomy was done through a right sub costal incision transverse $5 \mathrm{~cm}$ in length $3 \mathrm{~cm}$ to right of midline and $3 \mathrm{~cm}$ below the right costal margin or less rectus muscle sparing.

2. Group-B: Conventional open cholecystectomy was done through right subcostal Conventional Kocher's incision with rectus muscle transaction.

Follow up of patients was done after one week of discharge for the removal of stitches and to note the wound infection, 2nd visit was done ten day after the first visit to note the wound infection. All the data regarding stay in hospital and compilations like sever pain, wound infection, and was collected in a specific designed proforma.

Data was analyzed by SPSS version 11 . Variables to be analyzed include hospital stay and complications like pain through visual analog scale, wound infection with Asepsis scoring system. The variable analyzed by using descriptive statistics of mean and standard deviation, like stay in hospital and age. Frequency and percentage for qualitative data like wound infection and gender. Independent sample t-test for quantitative data like mean hospital stay and Chi-square for qualitative variables like wound infection and sever pain. $\mathrm{P}$ value $<0.05$ was taken as significant.

\section{RESULTS}

Total 100 patients were admitted from OPD of Teaching Hospital Dera Ghazi Khan, fulfilling inclusion criteria. Demographic information was recorded. All admitted patients were diagnosed based on history, clinical assessment and significant examinations. Mean age of all patients was $39.96 \pm 3.84$ years. Age range of patients was 30- 48 years. Mean age Group-A $38.66 \pm 4.33$ and Group B 41.26 2.76 years (Table-I).
Gender distribution of patients shows that in Group-B there were 7 male and 43 female patients. In Group-A there were 10 male and 40 female patients respectively (Table-II).

Mean hospital stay for all patients was $4.20 \pm 1.49$ days. Hospital stay ranges between 2-8 days. Group-A 5.38 \pm 1.15 and Group-B mean hospital stay was $3.02 \pm 0.58$ days (TableIII).

At 1 st visit $14(28 \%)$ patients in Group-B and only $1(2 \%)$ patient in Group-A had wound infection. According to P-value wound infection was significantly affiliated with treatment group. Patients in Group-A had less infection rate as compared to Group-B patients. i.e. ( $P$ value $=0.000)$ whereas at 2 nd visit $8(16 \%)$ patients in Group-B and 3 patients in Group-A suffered from wound infection. At 2 nd visit wound infection was statistically same in both treatment groups. i.e. $(P$-value $=0.110)($ TableIV).

Pain status was assessed in both treatment groups at 12 hours. It was observed that in Group-B only $44(88 \%)$ of the patients had severe pain whereas only $12(24 \%)$ of the patients in Group-A had severe pain. Keeping in mind this results rate of severe pain at 12 th hour was high in Group-B patients as compared to Group-A patients. i.e. $(P$-value $=0.000)$ (Table-V).

So it can be said that Mini Cholecystectomy is effective in the management of cholelithiasis in terms of wound infection with Asepsis scoring system (Figure-I) and severity of pain through visual analog system (Figure-II) experienced by patients.

Table-I: Descriptive statistics for age (years) in treatment group.

\begin{tabular}{|l|c|c|c|}
\hline & Group-A & Group-B & Total \\
\hline $\mathbf{N}$ & 50 & 50 & 100 \\
\hline Mean & 38.66 & 41.26 & 39.96 \\
\hline $\begin{array}{l}\text { Standard } \\
\text { Deviation }\end{array}$ & 4.33 & 2.76 & 3.84 \\
\hline Minimum & 30 & 36 & 30 \\
\hline Maximum & 48 & 48 & 48 \\
\hline
\end{tabular}

Group-A = Mini Cholecystectomy Group-B = Conventional Cholecystectomy 
Table-II: Gender distribution of patients in treatment groups.

\begin{tabular}{|c|c|c|c|c|}
\hline \multirow{2}{*}{} & \multicolumn{2}{|c|}{ Group } & \multirow{2}{*}{ Total } \\
\cline { 3 - 5 } & Male & Group-A & Group-B & 17 \\
\hline \multirow{2}{*}{$\begin{array}{c}\text { Gender Of } \\
\text { Patient }\end{array}$} & Female & $40(20 \%)$ & $7(14 \%)$ & 83 \\
\hline Total & & 50 & $43(84 \%)$ & 100 \\
\hline
\end{tabular}

Group-A= Mini Cholecystectomy

Group-B = Conventional Cholecystectomy

Table-III: Descriptive statistics for hospital stay (days) in treatment group.

\begin{tabular}{|c|c|c|c|}
\hline & Group-A & Group-B & Total \\
\hline $\mathbf{N}$ & 50 & 50 & 100 \\
\hline Mean & 3.02 & 5.38 & 4.20 \\
\hline Standard Deviation & 0.58 & 1.15 & 1.49 \\
\hline Minimum & 2 & 4 & 2 \\
\hline Maximum & 5 & 8 & 8 \\
\hline
\end{tabular}

Group-A= Mini Cholecystectomy

Group-B= Conventional Cholecystectomy

Table-IV: Wound infection at $1^{\text {st }} \& 2^{\text {nd }}$ visit in treatment group.

\begin{tabular}{|c|c|c|c|c|c|}
\hline \multicolumn{2}{|c|}{} & \multicolumn{2}{c|}{$1^{\text {st }}$ Visit } & \multicolumn{2}{c|}{$2^{\text {nd }}$ Visit } \\
\cline { 3 - 6 } & Group-A & Group-B & Group-A & Group-B \\
\hline \multirow{3}{*}{ Wound Infection } & Yes & $1(2 \%)$ & $14(28 \%)$ & $3(6 \%)$ & $8(16 \%)$ \\
\cline { 2 - 6 } & No & $49(98 \%)$ & $36(72 \%)$ & $47(94 \%)$ & $42(84 \%)$ \\
\hline \multicolumn{2}{|c|}{ P-value } & \multicolumn{2}{|c|}{0.000} & \multicolumn{2}{c|}{0.110} \\
\hline
\end{tabular}

Group-A= Mini Cholecystectomy

Group-B= Conventional Cholecystectomy

Table-V: Severe pain at $12^{\text {th }}$ hours in treatment groups.

\begin{tabular}{|c|c|c|c|c|}
\hline \multicolumn{2}{|c|}{} & \multicolumn{2}{|c|}{ Group } & \multirow{2}{*}{ Total } \\
\cline { 3 - 5 } \multicolumn{2}{|c|}{} & Group-A & Group-B & 56 \\
\hline $\begin{array}{c}\text { Severe Pain at } 12 \\
\text { Hours }\end{array}$ & Yes & $12(24 \%)$ & $44(88 \%)$ & 44 \\
\cline { 2 - 5 } & No & $38(76 \%)$ & $6(12 \%)$ & 100 \\
\hline \multicolumn{2}{|c|}{ Total } & 50 & 50 & \\
\hline
\end{tabular}

P-value $=0.000$ (Significant: P-value $<0.05$ )

Group-A= Mini Cholecystectomy

Group-B = Conventional Cholecystectomy 


\begin{tabular}{|c|c|c|c|c|c|c|}
\hline \multirow[b]{2}{*}{$\begin{array}{l}\text { Wound } \\
\text { characteristicas }\end{array}$} & \multicolumn{6}{|c|}{ Proportion of wound affected (\%) } \\
\hline & $\mathbf{0}$ & $<20$ & $20-39$ & $40-50$ & $60-79$ & $>80$ \\
\hline Serous exudates & $\mathbf{0}$ & 1 & 2 & $\mathbf{3}$ & 4 & $\mathbf{5}$ \\
\hline Erythema & $\mathbf{0}$ & 1 & 2 & $\mathbf{3}$ & 4 & 5 \\
\hline Purulent exudates & $\mathbf{0}$ & 2 & 4 & 6 & 8 & 10 \\
\hline $\begin{array}{l}\text { Separation of } \\
\text { deep tiosues }\end{array}$ & $\mathbf{0}$ & 2 & 4 & 6 & $\mathbf{8}$ & 10 \\
\hline \multicolumn{5}{|l|}{ Criteria } & \multicolumn{2}{|c|}{ Points } \\
\hline \multicolumn{7}{|l|}{ Additional treatment } \\
\hline \multicolumn{5}{|l|}{ Antibiotics } & \multicolumn{2}{|c|}{10} \\
\hline \multicolumn{5}{|c|}{ Drainage of pus under local anesthesia } & \multicolumn{2}{|c|}{5} \\
\hline \multicolumn{5}{|c|}{ Debridement of wound (general anesthesia) } & \multicolumn{2}{|c|}{10} \\
\hline \multicolumn{5}{|c|}{ Serous discharge } & \multicolumn{2}{|c|}{ Daily 0-5 } \\
\hline \multicolumn{5}{|l|}{ Erythema } & \multicolumn{2}{|c|}{ Daily 0-5 } \\
\hline \multicolumn{5}{|c|}{ Purulent exudates } & \multicolumn{2}{|c|}{ Daily 0-10 } \\
\hline \multicolumn{5}{|c|}{ Separation of deep tissues } & \multicolumn{2}{|c|}{ Daily 0-10 } \\
\hline \multicolumn{5}{|c|}{ lsolation of bacteria } & \multicolumn{2}{|c|}{10} \\
\hline \multicolumn{5}{|c|}{ Stay as inpatient prolongod over 14 days } & \multicolumn{2}{|c|}{5} \\
\hline \multicolumn{2}{|l|}{ Total score } & \multicolumn{5}{|c|}{ Category of infoction } \\
\hline \multicolumn{2}{|l|}{$0-10$} & \multicolumn{5}{|c|}{ Satistactory healing } \\
\hline \multicolumn{2}{|l|}{$11-20$} & \multicolumn{5}{|c|}{ Disturbance of healing } \\
\hline \multicolumn{2}{|l|}{$21-30$} & \multicolumn{5}{|c|}{ Minor wound infection } \\
\hline \multicolumn{2}{|l|}{$31-40$} & \multicolumn{5}{|c|}{ Moderate wound infoction } \\
\hline \multicolumn{2}{|l|}{40} & Severe & wound it & nfection & & \\
\hline
\end{tabular}

Figure-I: Asepsis scoring system.

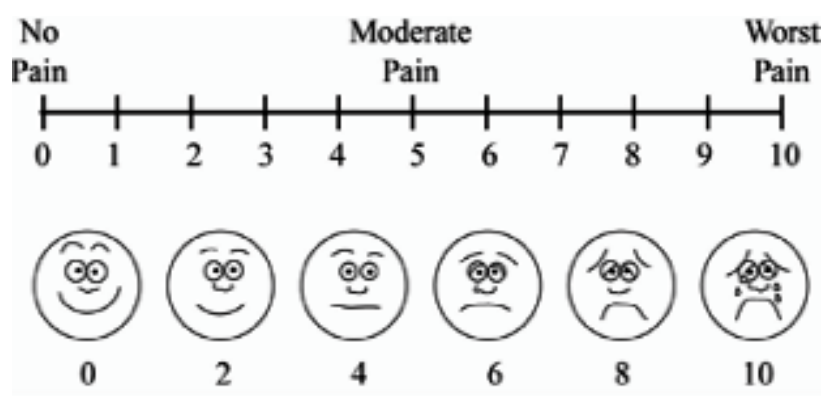

Figure-II: Visual analog scale.

\section{DISCUSSION}

The incidence of postoperative complication is significantly decreased with minimum invasive cholecystectomy or laparoscopic cholecystectomy as compared to open cholecystectomy as well as there is shortening of hospital stay and early to rejoin working ${ }^{[11]}$.

With the acceptance miniaturization and sophistication in the surgical gadgets resulted minimal invasive surgery with gradual reduction in length of abdominal wall incision as compared to the open cholecystectomy. Sub costal incision smaller then $8 \mathrm{~cm}$ length is defined as mini cholecystectomy and it can be performed even with a available conventional equipments and gained popularity as low cost alternative to laparoscopic cholecystectomy more over mini cholecystectomy. It is more advantageous as it does not need delicate equipments and specifically trained laparoscopic medical assistance. Currently minimal invasive procedure like mini cholecystectomy and laparoscopic cholecystectomy has almost replaced the traditional cholecystectomy with big incision ${ }^{[11]}$. Though mini cholecystectomy is an open technique yet it can be considered as a good substitute for removal of gall bladder stone for surgeons who are not well accustomed with laparoscopic cholecystectomy ${ }^{[12]}$.

Laparoscopy is gold standard for cholecystectomy because of decrease pain, hospital stay and wound complication but it need expertise, more learning cure, its cost is slightly high and it has high incidence of common bile duct injuries ${ }^{[13]}$.

Balasubramanian $A$ et al compare the mean age and gender distribution of 45 years (range $17-78$ years), 37 males (14.9\%) and 211 females $(85 \%)$ which is comparable with the mean age of $39.96 \pm 3.84$ years and 7 male, 43 female of Group-A and 10 male and 40 female of Group B in our study ${ }^{[14]}$.

A local study from Karachi reported age range of patients 25-70 years with female dominancy $(90 \%)$ who presented with cholelithiasis ${ }^{[3]}$. Another local study from Multan reported age range of patients who presented with cholelithiasis was $<40(28 \%)>50(40 \%)$ years. Female presentation ( $84 \%)$ was high as compared to male patients with cholelithiasis ${ }^{[10]}$. A local study from Lahore reported mean age of patients who presented with cholelithiasis was 43 years with age range 1877 years. Females presentation with cholelithiasis was higher as compared to male patients ${ }^{[4]}$.

According to the results of an Indian study the age range of patients who presented with cholelithiasis was 9 to 70 years. The mean age incidence was 41.55 yrs. Male: female ratio was $1: 2.75^{[15]}$. The age incidence of present study is comparable with the other local \& international studies. In contrast to Western countries, the Pakistani patients are younger in age. Various factors like shorter life span, racial, socioeconomic and dietary factors have been implicated. The gender distribution of current 
study i.e. female: $83 \%$ \& male: $17 \%$ compares well with the other studies. There is predictable proof that the gall bladder illnesses are progressively basic in females in all age gatherings. Down et al in 1983 revealed that it is the progesterone instead of estrogen which is liable for cholelithiasis ${ }^{[15,16]}$. Mean hospital stay in Mini Cholecystectomy was $3.02 \pm 0.58$ with range for hospital stay was (2-5) days and in conventional cholecystectomy was $5.38 \pm 1.15$ days with age range was (4-8) days respectively.

Study from Karachi reported mean hospital stay of 2 days with mini cholecystectomy ${ }^{[3]}$. Patients who were treated with traditional open cholecystectomy; the usual hospital stay remained 8.66 days with most limited stay of 6 days and longest stay of 10 days. While patients who were treated with mini cholecystectomy, the mean hospital stay was 3.33 days with most brief of 2 days and longest of 5 days ${ }^{[10]}$ Study from Lahore reported that average postoperative hospital stay after mini cholecystectomy was 2 days (1-5 days). All patients returned back to work within 2 weeks of surgery ${ }^{[4]}$.

A normal post-operative hospital stay of 3.3 days was additionally appeared in a study performed at department of gastroenterology surgery, Syth GS Medical College, Mumbai. Another study directed in department of general surgery, Genoa-Nervi Hospital, Italy demonstrated the normal postoperative remain was 2 days. In a study performed at All India Institute of Medical Sciences, New Dehli, in 1994 additionally demonstrated the normal postoperative hospital stay of 2.6 days ${ }^{[17]}$.

Another Indian study in which comparison of conventional and mini colecystectomy was done they reported average hospital stay as 10.8 days for conventional and 6.4 days with minicholecystectomy ${ }^{[15]}$. Even in the advance era mini cholecystectomy categorize as the superior efficacy over the customary open cholecystectomy with a shorter hospital stay and less analgesic demand. On the basis of these reasons it is preferred by the surgeons working in the rural environment with meager, inefficient expertly and non-availability of equipment's. Working environment and affordability in our region is also poor that is why we have preferred mini cholecystectomy instead of laparoscopic cholecystectomy over the open cholecystectomy ${ }^{[18]}$.

There were 3 local studies in which reported infection rate was $2 \%$ on with mini cholecystectomy in the management of cholelithiasis ${ }^{[3,4,9]}$. Whereas in a local comparative study infection rate was $24 \%$ in conventional cholecystectomy and $4 \%$ in mini cholecystectomy ${ }^{[10]}$. Hedawoo in his study reported wound infection rate $3.33 \%$ in the minilaparotomy group compared to $13.33 \%$ in the standard open group ${ }^{[15]}$. Watanpa in his study reported infection rate of $2.8 \%$ with the use of Mini-cholecystectomy ${ }^{[19]}$. In this study at $1^{\text {st }}$ visit post operatively wound infection rate was $2 \%$ in mini Cholecystectomy group and in open group wound infection was in $28 \%$ patients. But at $2^{\text {nd }}$ visit wound infection were present $6 \%$ patients in mini Cholecystectomy group and $16 \%$ patients in open group. AT $2^{\text {nd }}$ visit the infection rate was statistically same in both treatment groups. A result of this study in terms of infection rate is comparable with local \& international studies who reported less infection rate with mini Cholecystectomy. Pain was assessed post operatively at $12^{\text {th }}$ hour. There were $24 \%$ patients in mini Cholecystectomy group who had pain in open group $88 \%$ of the patients had pain. Significant difference was present in both treatment groups when it comes to postoperative pain assessment. With mini cholecystectomy incidence of post-operative pain was less.

Study done by Manan reported a significant difference in occurrence of pain post operatively with the use of mini and open Cholecystectomy technique. In open Cholecystectomy $56 \%$ of the patients experienced severe pain wile in mini cholecystectomy only $16 \%$ of the patients reported that they had severe pain ${ }^{[10]}$

A study was conducted in K.V.S.S. Site Hospital, Karachi, which discussed 10 years, experience on mini cholecystectomy versus 10 years' experience of conventional cholecystectomy. In this study mini cholecystectomy was performed through a small (about $3.5 \mathrm{~cm}$ ) sub costal incision and cases were studied for operative time, postoperative pain, postoperative hospital stay, resumption of daily life and work. It states that as a result of comparison of 2 procedures it is concluded that mini 
cholecystectomy is superior to conventional cholecystectomy ${ }^{[18]}$.

A study conducted by Hakan Demir et al compared the hospital stay, complications and return to work among the patients of mini cholecystectomy, Iaparoscopic cholecystectomy and open cholecystectomy in their study although laparoscopic cholecystectomy is advantageous even then mini cholecystectomy had a significant edge over open cholecystectomy in term of hospital stay, postoperative complications and return to daily activity. So it can be considered as an acceptable alternative to laparoscopic cholecystectomy in certain special circumstances $^{[20]}$.

Another study conducted in North Surgical Ward, Mayo Hospital, Lahore and results of this study narrate that less operative time, less postoperative pain and early return to work is seen after mini-cholecystectomy (incision size up to $5 \mathrm{~cm}$ ) than conventional cholecystectomy ${ }^{[21]}$.

Another study conducted by Muhammad Iftikhar et al compare the laparoscopic cholecystectomy with small incision cholecystectomy which is comparable with our study with the better results of mini cholecystectomy in areas where laparoscopic facilities are not available ${ }^{[22]}$.

A study done at Department of Surgery, Bahawal Victoria Hospital, Bahawalpur contrasting most recent laparoscopic versus traditional cholecystectomy with the laparoscopic system having less hospital remain and wound contamination which is comparable with our study in which small incision cholecystectomy show better outcomes with less hospital remain and wound infection ${ }^{[23,24]}$.

The decreased incidence of postoperative complication is multifactorial in origin. In minicholecystectomy there is less tissue trauma, so there is less postoperative pain, short hospital stay and less chances of development of bad looking scar.

\section{CONCLUSION}

Mini cholecystectomy is an excellent alternative to conventional cholecystectomy as far as postoperative hospital stay, postoperative infection and pain as well as with good cosmetics concerned with scar. Minicholecystectomy is associated with less discomfort and minimum postoperative complications for the patients.

\section{CONFLICT OF INTEREST:}

All authors disclose no conflict of interest.

\section{GRANT SUPPORT\& FINANCIAL DISCLOSURES: None.}

\section{REFFERENCES:}

1. Saeed A, Nawaz M, Noreen A, Ahmad S. Early cholecystectomy in acute cholecystitis: experience at DHQ Hospital Abbottabad. Journal of Ayub Medical College Abbottabad. 2010;22(3):182-184.

2. Chalkoo M, Ahanger S. The Historical Perspective, Current Advancements and Innovations in Laparoscopic Cholecystectomy. journal of the Pakistan Medical Association. 2012;2(3):5-6.

3. Saeed N, Nasir T, Burki B, Channa GA. MiniCholecystectomy: A Feasible Option. Journal of Ayub Medical College Abbottabad. 2010 Sep 1;22(3):68-70.

4. Rana HN, Hasan F, Tahir M, Ali M, Saleem $\mathrm{R}$, Khan HA. Mini Cholecystectomy through a $5 \mathrm{~cm}$ Subcostal Incision Experience at NSSSH Lahore. Pakistan Journal of Medical \& Health Sciences.2010;5(4):120-125.

5. Purkayastha S, Tilney HS, Georgiou P, Athanasiou T, Tekkis PP, Darzi AW. Laparoscopic cholecystectomy versus minilaparotomy cholecystectomy: a metaanalysis of randomised control trials. Surgical endoscopy. 2007;21(8):1294300. Doi:10.1007/s00464-007-9210-3.

6. Keus F, Ahmed Ali U, Noordergraaf GJ, Roukema JA, Gooszen HG, Van Laarhoven CJ. Laparoscopic vs. small incision cholecystectomy: Implications for pulmonary function and pain. A randomized clinical trial. Acta anaesthesiologica scandinavica. 2008;52(3):363-373. Doi:10.1111/ j.1399-6576.2007.01488.x.

7. Chalkoo M, Ahangar S, Durrani AM, Chalkoo S, Shah MJ, Bashir MI. Mini-lap 
cholecystectomy: modifications and innovations in technique. International Journal of Surgery. 2010;8(2):112-117. Doi:10.1016/j.ijsu.2009.11.007.

8. Khan N, Haleem A, Ahmad I, Jan A. Cholecystectomy through mini laparotomy incision. Gomal Journal of Medical Sciences. 2009;7(2).

9. Amir M, Haider MH. Mini-open cholecystectomy in the management of cholelithiasis. Journal of the College of Physicians and Surgeons--pakistan: JCPSP. 2007 May 1;17(5):269-271. Doi: 05.2007/jcpsp.269271.

10. Manan A, Ahmed I, Aftab F. Conventional open and mini cholecystectomy. The Professional Medical Journal. 2007;14(02):212-217.

11. Castro PM, Akerman D, MUnhoz CB, Sacramento ID, Mazzurana M, Alvarez GA. Laparoscopic cholecystectomy versus minilaparotomy in cholelithiasis: systematic review and meta-analysis. $A B C D$. Arquivos Brasileiros de Cirurgia Digestiva ( $\mathrm{S}$ ão Paulo). 2014 Jun;27(2):148-153. Doi:10.1590/S010267202014000200013.

12. Almahjoub A, Elfaedy O, Mansor S, Rabea A, Abdulrahman A, Alhussaen A. Minicholecystectomy versus laparoscopic cholecystectomy: a retrospective multicentric study among patients operated in some Eastern Libyan hospitals. Turkish Journal of Surgery. 2019;35(3: 185-190. Doi: 10.5578/turkjsurg.4208 PMID: 32550326.

13. Deziel DJ, Millikan KW, Economou SG, Doolas A, Ko ST, Airan MC. Complications of laparoscopic cholecystectomy: a national survey of 4,292 hospitals and an analysis of 77,604 cases. The American journal of surgery. $1993 ; 165(1): 9-14$. Doi:10.1016/S0002-9610(05)80397-6.

14. Balasubramanian A, Cheddie S, Naidoo NM, Singh B. An evaluation of minilaparotomy cholecystectomy in the laparoscopic era: a rural experience. South African Journal of Surgery.
2018;56(2):36-40. Doi: $10.17159 / 2078-$ 5151/2018/v56n2a2287.

15. Hedawoo J, Rathod V, Kamath B. Minilaparotomy Cholecystectomy-A Feasible Option. Available from: https://www.bhj.org.in/journal/2007_49 02_april/html/org_article_285-291.html

16. Down RH, Whiting MJ, Watts JM, Jones W. Effect of synthetic oestrogens and progestagens in oral contraceptives on bile lipid composition. Gut. 1983;24(3):253259. Doi: 10.1136/gut.24.3.253

17. Supe AN, Bapat VN, Pandya SV, Dalvi AN, Bapat RD. Laparoscopic Versus Mini-Lap Cholecystectomy for Gallstone. Indian Journal Gastroenterolgy. 1996;15(3):9496.

18. Tariq S, Sarfraz F, Wali F, Sahar NU, Fatima $R$. Ten years experience of Mini Cholecystectomy versus ten years experience of conventional Cholecystectomy at KVSS Site Hospital, Kar. Pakistan Journal of Surgery. 2004;20(1):8-10.

19. Watanapa P. Mini cholecystectomy: a personal series in acute and chronic cholecystitis. Hpb. 2003;5(4):231-234. Doi:10.1080/13651820310001379

20. Demir H, Karaman K, Palabıyık O, Sonbahar T, Tastuna A, Zengin I. The Rationality of Mini-Laparotomy Cholecystectomy in Symptomatic Gallbladder Disease: A Retrospective Cohort Study. Gastroenterology Hepatology. 2016;5(7):00169. DOI: 10.15406/ghoa.2016.05.00169.

21. Chand S, Ali AA, Khan AF, Chaudhry AM. Randomized trial of standard cholecystectomy versus minicholecystectomy. Annals of King Edward Medical College. 1997;3:106-108.

22. Iftikhar M, Alam J, Nasir IU, Farooq M. Comparison of small-incision open cholecystectomy versus laparoscopic cholecystectomy for patients with symptomatic cholelithiasis. Kobe Journal of Medical Sciences. 2015;8(3):339-342.

23. Ahmed SA, Iqbal TA, Abdullah SM. Open 
Cholecystectomy versus Laparoscopic Cholecystectomy: A Comparative Study.

24. Pakistan Journal of Medical \& Health Sciences. 2014;8(2):382-385. Ummair M, Khan MF, Khalil A, Waheed R, Shah AA. Frequency of conversion to open cholecystectomy in patients under going laparoscopic cholecystectomy: - a retrospective analysis. Journal of Medical Sciences. 2019; 27: (2) 120-124.

\section{Authors' Contribution:}

Uzair Karim Qaisrani: Study Design and final approval of manuscript.

Muhammad Faizan: Data collection, statistical analysis and literature search.

Zarnab Siddique: Over all Supervision of data collection, analysis and manuscript writing.

Muhammad Khalid: Help in data collection analysis and final draft of study.

Kiran Bashir: Help in data collection analysis and final draft of study.

Asim Bhatti: Manuscript writing and proof reading.

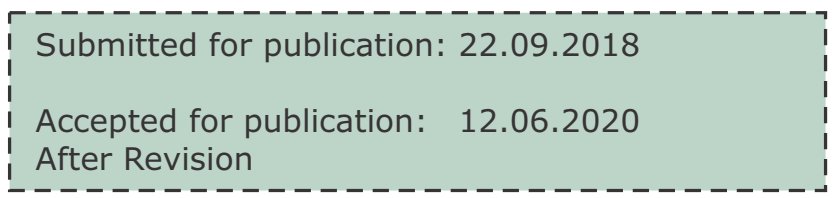

